\title{
Training Strategy on Intercultural Communicative Competence in English Teaching
}

\author{
Chuang Ding \\ Public English Department, Liaoning University of International Business and Economics, Dalian, \\ 116052, China \\ 2828921@qq.com
}

Keywords: English teaching; intercultural communicative competence; structure model; training mode; training strategy

\begin{abstract}
Intercultural communicative competence is the ultimate goal of foreign language education, and foreign language teaching needs the theoretical guidance of intercultural communication. This paper is aimed at the problems of foreign language teaching. Based on the structure model and training model of intercultural communication ability, the training strategy is put forward, Including: the use of network resources to feel real context, improve the quality of teachers, through the cultural contrast to deepen the understanding of mother tongue culture, pay attention to the cultivation of students' autonomous learning ability, in English teaching materials, the integration of cross-cultural communication, to achieve language ability and communicative ability training, optimize the curriculum setting and teaching content, research vocabulary and idioms cultural background. The research results of this paper have important significance for improving the quality of English teaching and strengthening students' intercultural communicative competence.
\end{abstract}

\section{Introduction}

The Ministry of Education announced the "College English curriculum teaching requirements" pointed out that "college English teaching objective is to cultivate students' English language proficiency, especially listening and speaking ability, so that students can use English in the future study, work and social interaction to communicate effectively, while enhancing their self-learning ability, enhance cultural awareness, in order to meet the needs of social development and international exchanges. College English course is not only a language course, but also a quality education course, which is also the knowledge and the knowledge of the world culture. Therefore, the design of College English curriculum should be fully considered to the students' cultural quality training and international cultural knowledge". English teaching, including vocabulary, grammar and discourse, and the ability to cross cultural communication is also the ability to develop[1].Because of the importance of intercultural communication lack of knowledge, the importance of English language teaching, usually only think of pronunciation, vocabulary and grammar, and so on, as long as you listen to, say, will read, will be able to communicate with foreigners, the ability to communicate with the basic skills of English. University teachers pay more attention to the language form of the students in English teaching, the language use is fluent, and less attention is paid to the specific circumstances of the use of language. All aspects of English Teaching in the form of light culture phenomenon is more serious, the general lack of system of cultural background knowledge education.

Language and culture are inseparable, language is the carrier of culture, but also an important part of culture. Language application is influenced and restricted by the cultural system [2,3]. Therefore, to master two languages, we must grasp the two culture. Only by crossing the target language country's cultural barrier, can we achieve the communication between the right and proper. One of the main goals of foreign language teaching is to cultivate students' intercultural communicative competence. Therefore, it is not only necessary to combine language study and cross-cultural research, but also the extension of foreign language teaching practice. Cross cultural communication and foreign language teaching are inseparable. Foreign language teaching should 
not only teach language knowledge, but also cultivate communicative competence. With the continuous development of economy and society, foreign exchanges are becoming more and more frequent, and the communication between countries is becoming more and more extensive. However, the foreign language education is obviously lagging behind. On the one hand, there is a negative effect on the examination oriented education. On the other hand, the traditional foreign language education is bound to the teacher's ideas. Intercultural communicative competence is the ultimate goal of foreign language education, and language education should be a cultural education in a large extent. Foreign language teaching should be guided by the theory of intercultural communication.

\section{Structure Model of Intercultural Communicative Competence}

Cross cultural communication ability is composed of knowledge factor, emotion factor, situation characteristic and mental activity characteristic, structure model is shown in Fig. 1 [4,5]. Among them, knowledge factor, which refers to the communicators should understand the target culture in the target culture, context, and people's demands for appropriate behavior and other information, it is the right interpretation of the communication object to convey the language and non-verbal information, but also the basis for the choice of appropriate communication. In the absence of intercultural communication knowledge, communication is unable to determine whether or not they are appropriate in the context of the target culture, which refers to the attitude of the communicators to the communicative objects and intercultural communication. Communication processing pressure and tolerate a stronger ability to vague and intercultural communicative competence in higher; factors of mental activity is the embodiment of knowledge and emotional factors, including verbal and non verbal expression and role play. Speech expression refers to how the individual uses language. Non verbal expressions including body language, time language, color language, space language, auxiliary language, etc.. Role play is related to context, which refers to how to use language and non language symbol in the target culture; Situation characterized by a certain period of time, including the relative or the combination of the situation, including the environment, and whether the purpose of the culture has been exposed, people play the role of social status difference, third party interference or participation.

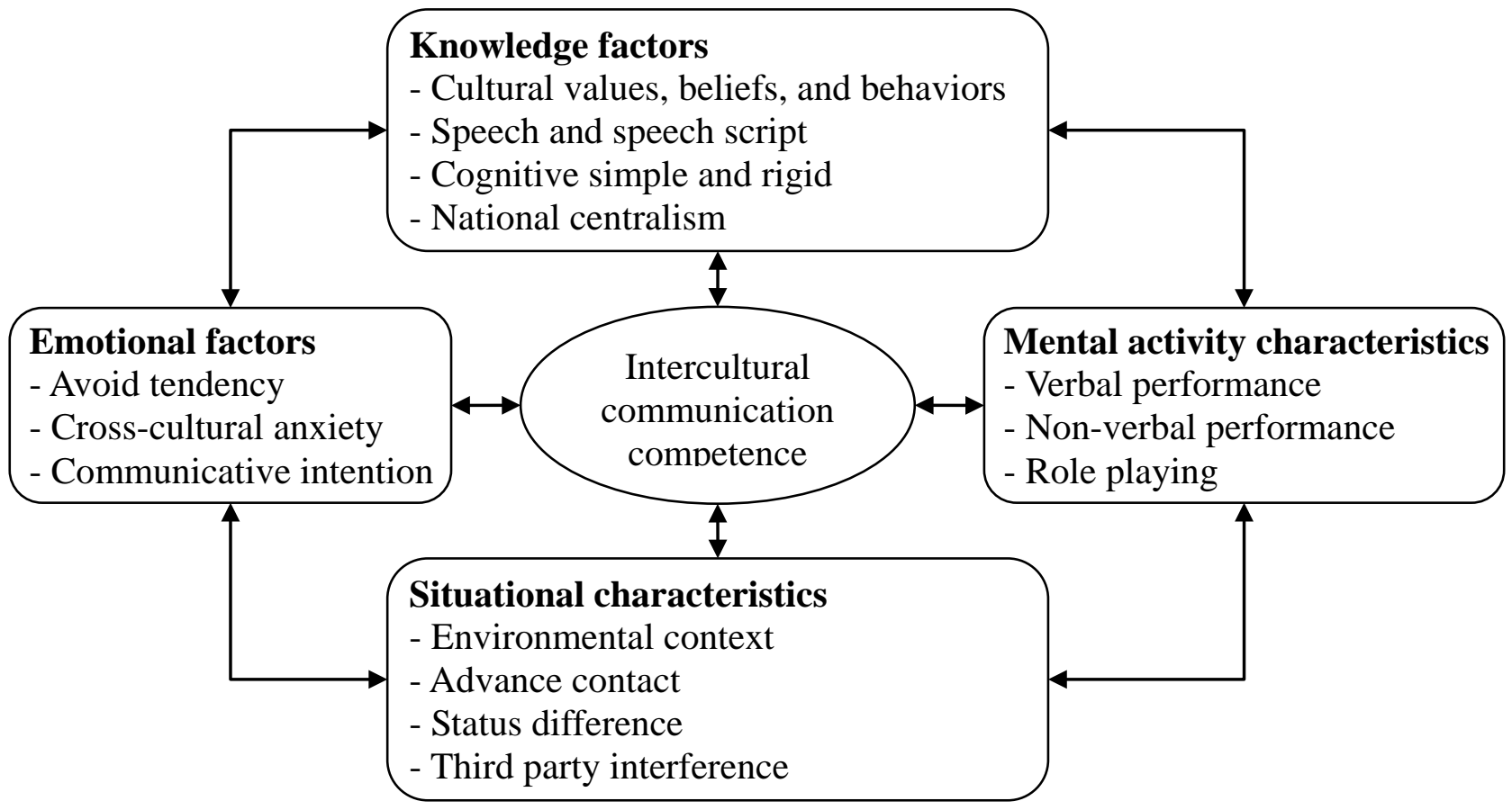

Fig. 1. Structure model on intercultural communication competence 


\section{Training Mode of Intercultural Communicative Competence}

Personnel training mode refers to the sum of the process of teaching content and curriculum system, management system and evaluation method, and the process of implementing talent education in accordance with the specific training objectives and talent specifications, in accordance with the specific training objectives and standards. That is, the training objectives and training standards of personnel and the method or means to achieve these objectives. It includes four meanings: training target and specification; In order to realize the educational process of training objectives and specifications, a set of management and evaluation system for the process of realizing the process, and the teaching methods, methods and means of matching the teaching process. intercultural communicative competence training mode is based on the needs of cross culture communication, and to guide the training of theory, training objectives, training principles, training content and training process, etc., in the global cultural awareness, cultural debugging ability, communication and cultural knowledge and practice ability, etc.. Cross cultural communication ability training mode is shown in Fig. 2.

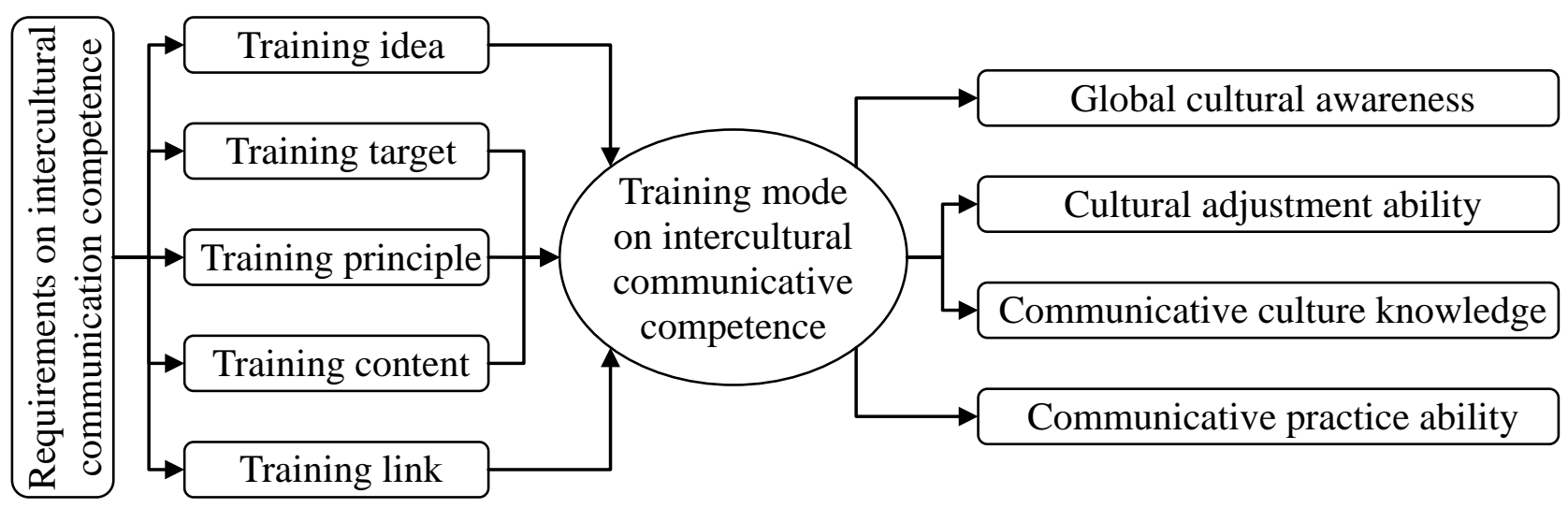

Fig. 2. Training mode on intercultural communicative competence 


\section{Training Strategy of Intercultural Communicative Competence}

English teaching should adopt flexible and varied methods to improve students' sensitivity to culture, develop cultural awareness and improve communication skills. Enable students to take the initiative to absorb and integrate into the new cultural environment, better grasp the use of this language. It is necessary to help students acquire a large amount of cultural content, which is necessary to achieve a large amount of cultural content. Teachers should use effective teaching method to permeate cultural elements in the teaching process, and students should take effective learning method to absorb English cultural connotation, and finally achieve the purpose of cross-cultural communication. The strategies of intercultural communication in English teaching mainly include the following aspects [6-10]:

(1) Using the network resources to feel the real context. Network environment has created favorable conditions for the cultivation of College Students' intercultural communicative competence. Network not only has the language and culture learning resources, but also is a great platform for intercultural communication. Including online radio broadcast, television programs, television programs, electronic newspapers, foreign websites, such as real reflection of the social aspects of the material, the students exposure to a relatively real cultural environment, the biggest feeling of foreign real cultural context, to understand the real life of foreigners, the accumulation of foreign cultural background, customs, lifestyle, social relations and other aspects of knowledge, improve cultural understanding. Make full use of modern network technology and resources to build a valuable learning environment to promote and support students' learning activities.

(2) Improve teachers' quality. Teacher is the key to realize the cultivation of intercultural communication competence, and the quality of English teachers directly influences the effect of the cultivation of students' intercultural communication competence. Many English teachers are familiar with the knowledge of the language and the structure of the grammar. When it comes to intercultural communicative competence, feel rich enough knowledge of their own culture and language ability is not strong, the teaching of English language and culture have fear of difficulty. Therefore, in the case of the conditions, English teachers should learn from foreign countries, in the language of the language of the national culture, and feel the difference between the language and culture of the British and American countries. It can also employ some foreign experts to train English teachers to improve their language skills and intercultural communication skills.

(3) To deepen the understanding of mother tongue culture through cultural contrast. Foreign language teaching target is difficult to rely solely on the completion of foreign language courses. Can not because of the emphasis on the cultural traditions of the target language, the cultural characteristics of the nation. English is constantly expanding the influence, the national culture is also in constant struggle, resulting in the interaction between the two. The cultural teaching in foreign language teaching and the culture of the two countries in the intersection and contradictions, cross cultural education to examine their own culture provides a good opportunity. In English education, to strengthen the Chinese culture, the research results of the comparison of English and Chinese in English textbooks. The differences between the native language and the target language culture, to understand what is the essence of national culture, which can be used to target culture. Efforts should be made to cultivate the awareness of the native culture of English learners in order to promote the students' Reflection on their own culture.

(4) Pay attention to cultivate students' autonomous learning ability. Autonomous learning is a kind of modern learning style which is relative to the traditional learning. It is the ability to manage their own learning ".Students as the subject of learning, not subject to other people, not subject to external interference. Through reading, listening, research, observation, practice and other means to make the knowledge to be sustained growth. The relationship between intercultural communicative competence and autonomous learning is the mutual influence and mutual promotion. Autonomous learning is an effective way to improve the ability of cross culture communication, and the ability of intercultural communication can be improved. Autonomous learning is the long-term goal of higher 
learning institutions and the way to develop the personal lifelong education. It is an effective way to improve and cultivate students' intercultural communicative competence.

(5) Integration of cross cultural communication in English teaching materials. In the English language stage, we should add the contents of the cultural knowledge and foreign culture. The contents of the teaching material are related to many aspects, such as politics, religion, culture, economy and so on, presents the differences between Chinese and Western culture. Teachers can use the existing teaching material and teaching focus on language knowledge and cultural background knowledge, cultural connotations permeate, key statement inspiration, cultural differences between Chinese and western language and cultural values differences, establish different teaching module. College English teaching is no longer a single language and grammar knowledge, but with the improvement of students' culture, broaden their horizons, cultivate their good values of cross culture teaching.

(6) The combination of language competence and communicative competence. Language ability is a finite rule system, so that the language users can understand the syntax of the sentence. Communicative competence is a kind of social and cultural competence, which is the ability to use language and non language means to communicate. Language learners in the process of language acquisition, not only the acquisition of language ability, but also include the ability to communicate. As language learning is conducted in a specific social environment, learners have the ability to judge the language, not only to see their master the grammar rules, but also to see the use of their language rules. Therefore, in the teaching of English, the language ability of the training should be combined with the communicative competence and cultural import, to cultivate English learners' effective use of English communicative competence.

(7) Optimize the curriculum and teaching content. College English curriculum, in addition to set up the integrated curriculum and listening and speaking, but also should be increased cross-cultural communication. Only with strong ability of "listening, speaking, reading, writing and translating", it does not have the basic ability to cross cultural communication and can not carry out effective cross-cultural communication. It is necessary to increase the content of intercultural communication in College English curriculum. Comparing the western culture with its own culture, to help students better understand the Chinese and Western culture, the formation of the global cultural awareness. A large number of words in the English language are rich in cultural elements and cultural connotations, and can tap the potential cultural factors from the English text, Reinforcement learning's interest in promoting students' intercultural communication awareness and ability.

Cultural background of vocabulary and idioms. Idioms are the essence of language, with a strong national color and distinctive cultural connotations. Vocabulary and idioms are the most part of the language which can reflect the characteristics of the national culture. A large number of words and idioms in English and Chinese are rooted in two distinct cultural environments. With different national image and cultural color, many words and idioms clearly reflect the differences between Chinese culture and American culture. Therefore, the study of vocabulary and idioms clearly reflects the differences between Chinese culture and American culture, the cultural background of vocabulary and idioms, and will be compared with a more detailed understanding of the culture and foreign culture.

\section{Conclusion}

With the rapid development of economy and society, many countries in the world have become more and more closely related to the economy, politics and culture. Therefore, the demand for the talents with intercultural communication competence is becoming more and more outstanding. The intercultural communicative competence has become the indispensable quality of the talents in the context of globalization, which is the requirement of the times and the necessity of social development. In order to adapt to the fierce international competition, China needs a large number of talents with excellent business skills, good language skills and strong intercultural communication competence. For a long time, foreign language teaching ideas and teaching methods, more emphasis on language knowledge and language skills training, ignoring the cultural factors, 
resulting from language and culture. This teaching mode of students, although there is a good language expression ability, said the sentence is fully in line with English grammar, but the ability of cross-cultural communication is very poor. The research results of this paper have put forward specific measures to cultivate students' intercultural communicative competence in English teaching process, which is of great significance in improving the quality of English teaching and strengthening students' intercultural communicative competence.

\section{References}

[1] X. G. Yang, G. Y. Liu, "On the cultivation of intercultural communicative competence in English Teaching," Contemporary Educational Science, vol. 17, no. 21, pp. 58-60, 2003.

[2] Sergey S. Khromov, Ludmila Yu, Minakova, "Intonation in the Context of Interlingual and Intercultural Communication," Procedia - Social and Behavioral Sciences, vol. 154, no. 28, pp. 412-416, 2014.

[3] Judith N. Martin, "Revisiting intercultural communication competence: Where to go from here," International Journal of Intercultural Relations, vol. 48, no. 9, pp. 6-8, 2014.

[4] L. Gao, F. Wang, "A tentative approach to intercultural communicative competence," Journal of Northwest University (Philosophy and Social Sciences Edition), vol. 37, no. 3, pp. 116-119, 2007.

[5] Baidu library, "Intercultural communicative competence," http://wenku.baidu.com/link?url=pr-uORfEpQMV8IXfk5OjvMHNZBLPFOJ9xpNGW8SL231 P3xXVtwOsyd1Rxmz29N6wICHgVFpixxW69Mj5VB1s11kUF00FLOs-5eE9RxLBosy, 2015-8-21.

[6] Y. Yang, "Research on structure and model of intercultural communication competence," Journal of Tianjin Foreign Studies University, vol. 21, no. 4, pp. 50-58, 2014.

[7] L. Shen, "Autonomous learning: an Effective way to Improving the Competence of University students Cross-cultural Communication," Journal of Jiaying University, vol. 28, no. 1, pp. 86-89, 2010.

[8] J. F. Shang, Q. C. Li, "The cultivation of students' intercultural communicative competence in College English Teaching," Education Exploration, vol. 33, no. 3, pp. 43-44, 2013.

[9] R. Q. Liu, "Deletion and correction strategy in English learners' intercultural communicative competence," Contemporary Education Sciences, vol. 30, no. 18, pp. 58-60, 2015.

[10] Y. Wang, L. Y. Wang, "On Improvement of Students' Intercultural Communicative Competence in College English Teaching in Local Universities," Journal of Xiangnan University, vol. 35, no. 6, pp. 95-98, 2014. 